University of Nebraska - Lincoln

DigitalCommons@University of Nebraska - Lincoln

$1-1-2005$

\title{
Roles for nutrients in epigenetic events
}

Anna M. Oommen

University of Nebraska - Lincoln, aoommen2@unl.edu

Jacob B. Griffin

University of Nebraska - Lincoln

Gautam Sarath

University of Nebraska - Lincoln, Gautam.sarath@ars.usda.gov

Janos Zempleni

University of Nebraska - Lincoln, jzempleni2@unl.edu

Follow this and additional works at: https://digitalcommons.unl.edu/biochemistrysarath

Part of the Biochemistry, Biophysics, and Structural Biology Commons

Oommen, Anna M.; Griffin, Jacob B.; Sarath, Gautam; and Zempleni, Janos, "Roles for nutrients in epigenetic events" (2005). Gautam Sarath Publications. 4.

https://digitalcommons.unl.edu/biochemistrysarath/4

This Article is brought to you for free and open access by the Biochemistry, Department of at DigitalCommons@University of Nebraska - Lincoln. It has been accepted for inclusion in Gautam Sarath Publications by an authorized administrator of DigitalCommons@University of Nebraska - Lincoln. 


\author{
Emerging Issues
}

\title{
Roles for nutrients in epigenetic events
}

\author{
Anna M. Oommen ${ }^{\mathrm{a}}$, Jacob B. Griffin ${ }^{\mathrm{a}}$, Gautam Sarath ${ }^{\mathrm{b}, \mathrm{c}}$, Janos Zempleni ${ }^{\mathrm{a}, \mathrm{d}, \mathrm{e}, *}$ \\ ${ }^{a}$ Department of Nutrition and Health Sciences, University of Nebraska at Lincoln, Lincoln, NE 68583-0806, USA \\ ${ }^{\mathrm{b}}$ USDA-ARS University of Nebraska at Lincoln, Lincoln, NE 68583-0939, USA \\ ${ }^{\mathrm{c}}$ Department of Entomology, University of Nebraska at Lincoln, Lincoln, NE 68583-0816, USA \\ ${ }^{\mathrm{d}}$ Department of Animal Science, University of Nebraska at Lincoln, Lincoln, NE 68583-0806, USA \\ ${ }^{\mathrm{e}}$ Department of Biochemistry, University of Nebraska at Lincoln, Lincoln, NE 68583-0664, USA \\ Received 24 July 2004; received in revised form 24 August 2004; accepted 27 August 2004
}

\begin{abstract}
The field of epigenetics is the study of modifications of DNA and DNA-binding proteins that alter the structure of chromatin without altering the nucleotide sequence of DNA; some of these modifications may be associated with heritable changes in gene function. Nutrients play essential roles in the following epigenetic events. First, folate participates in the generation of $S$-adenosylmethionine, which acts as a methyl donor in the methylation of cytosines in DNA; methylation of cytosines is associated with gene silencing. Second, covalent attachment of biotin to histones (DNA-binding proteins) plays a role in gene silencing and in the cellular response to DNA damage. Third, tryptophan and niacin are converted to nicotinamide adenine dinucleotide, which is a substrate for poly(ADP-ribosylation) of histones and other DNA-binding proteins; poly(ADP-ribosylation) of these proteins participates in DNA repair and apoptosis. Here we present a novel procedure to map nutrient-dependent epigenetic marks in the entire genomes of any given species: the combined use of chromatin immunoprecipitation assays and DNA microarrays. This procedure is also an excellent tool to map the enzymes that mediate modifications of DNA and DNA-binding proteins in chromatin. Given the tremendous opportunities offered by the combined use of chromatin immunoprecipitation assays and DNA microarrays, the nutrition community can expect seeing a surge of information related to roles for nutrients in epigenetic events.
\end{abstract}

(C) 2005 Elsevier Inc. All rights reserved.

Keywords: Biotin; Chromatin immunoprecipitation assay; CpG dinucleotides; DNA microarray; Folate; Histones; Methylation; Niacin

\section{Introduction}

DNA and DNA-binding proteins make up the bulk of chromatin. DNA-binding proteins comprise a diverse group of compounds including histones, high-mobility group proteins, transcription factors and enzymes that mediate covalent modifications of DNA (see below). Classically, the nucleotide sequence in DNA has been considered as the sole driver of heredity. Consistent with this point of view, phenotypic traits were thought of as being determined by genetic mutations and recombinations. Recently, this point of view has been changed dramatically by epigeneticists. The field of epigenetics is the study of chemical modifications of DNA and DNA-binding proteins that alter the

* Corresponding author. Department of Nutrition and Health Sciences, University of Nebraska at Lincoln, NE 68583-0806, USA. Tel.: +1 402472 3270; fax: +1 4024721587.

E-mail address: jzempleni2@unl.edu (J. Zempleni). structure of chromatin without altering the nucleotide sequence of the DNA; some of these modifications may be associated with heritable changes in gene function.

Articles published in the "Emerging Issues" series of the Journal of Nutritional Biochemistry are not intended to provide readers with an in-depth review of a given topic. Rather, the purpose of this series is to draw the readers' attention to recent developments with far-reaching implications for nutrition sciences. Here we will briefly review nutrient-dependent epigenetic events and present a novel tool to study roles for nutrients in epigenetic events: the combined use of chromatin immunoprecipitation (ChIP) assays and DNA microarrays.

\section{Roles for nutrients in epigenetic events}

Most epigenetic mechanisms target DNA and various DNA-binding proteins. In this section, we review three important examples for nutrient-dependent epigenetic events. 


\subsection{Methylation of $D N A$}

Promoter regions of many genes are rich in $\mathrm{CpG}$ dinucleotides [1]. Carbon 5 of cytosine in $\mathrm{CpG}$ dinucleotides is a prime target for methylation by DNA methyltransferases (DNMT) [1]. Depending on cell type or tissue, $3-4 \%$ of all cytosines in vertebrate DNA and $70 \%$ of cytosines in $\mathrm{CpG}$ dinucleotides are 5-methylated [1]. The following DNMT have been characterized: DNMT1, DNMT2, DNMT3a, DNMT3b and DNMT3L; catalytic activity has been shown only for DNMT1, DNMT3a and DNMT3b [1]. Methylation of cytosines is a heritable modification of DNA. However, the following mechanisms are available to remove methylation marks in vivo: (1) enzyme-mediated removal of methyl groups, although the enzymes involved have not yet been identified, and (2) passive removal of methyl groups if methylation is not maintained at the time of replication [1].

DNMT utilize $S$-adenosylmethionine as a methyl donor [1]. Folate plays a unique role in the generation of $S$-adenosylmethionine [1]. Briefly, methylentetrahydrofolate reductase catalyzes the conversion of 5,10-methylenetetrahydrofolate to 5-methyltetrahydrofolate. The latter donates a methyl group to convert homocysteine to methionine. Methionine adenosyl transferase ligates methionine and adenosine to produce $S$-adenosylmethionine. Methylenetetrahydrofolate reductase deficiency results in hypomethylation of DNA, consistent with a role for folate in DNA methylation [1]. Nutrients other than folate also play roles in one-carbon metabolism: choline and methionine are the major dietary sources of methyl groups, whereas vitamins B-6 and B-12, riboflavin and zinc are coenzymes and cofactors, respectively, for various steps in one-carbon metabolism [1].

Methylation of $\mathrm{CpG}$ islands is associated with transcriptional repression and provides a mean to control gene expression. DNA methylation plays a role in allele-specific gene expression (genomic imprinting), heritable transcriptional silencing of parasitic sequence elements and $\mathrm{X}$ chromosome inactivation [1]. Impaired DNA methylation is associated with perinatal death, decreased fertility, abnormal fetal development and tumorigenesis [1].

\subsection{Biotinylation of histones}

Histones are small proteins (11 to $22 \mathrm{kDa}$ ) that mediate the folding of DNA into chromatin. The following five major classes of histones have been identified in eukaryotic cells: H1, H2A, H2B, H3 and H4 [2]. DNA is wrapped around octamers of core histones, each consisting of one $\mathrm{H} 3-\mathrm{H} 3-\mathrm{H} 4-\mathrm{H} 4$ tetramer and two $\mathrm{H} 2 \mathrm{~A}-\mathrm{H} 2 \mathrm{~B}$ dimers, to form the nucleosomal core particle. Histone $\mathrm{H} 1$ associates with the DNA connecting nucleosomal core particles. Nucleosomes are stabilized by electrostatic interactions between negatively charged phosphate groups in DNA and positively charged $\varepsilon$-amino groups (lysine residues) and guanidino groups (arginine residues) in histones.
Histones consist of a globular C-terminal domain and a flexible N-terminal tail [2]. The amino terminus of histones protrudes from the nucleosomal surface; lysines, arginines, serines and glutamates in the amino terminus are targets for acetylation, methylation, phosphorylation, ubiquitination, poly(ADP-ribosylation) and sumoylation [2-6]. These modifications play important roles in chromatin structure, regulating processes such as transcriptional activation or silencing of genes, DNA repair and mitotic and meiotic condensation of chromatin.

Recently, a novel posttranslational modification of histones has been identified in human cells: biotinylation of lysine (K) residues [7]. The following biotinylation sites have been identified in human histones: $\mathrm{K} 9$ and $\mathrm{K} 13$ in histone $\mathrm{H} 2 \mathrm{~A}$ (unpublished observation); $\mathrm{K} 4, \mathrm{~K} 9$ and $\mathrm{K} 18$ in histone $\mathrm{H} 3$ [8]; and $\mathrm{K} 8$ and $\mathrm{K} 12$ in histone $\mathrm{H} 4$ [7]. Biotinylation of histones is catalyzed by biotinidase [9] and holocarboxylase synthetase [10]. Biotinylation of histones plays a role in processes such as gene silencing, cell proliferation and DNA repair or apoptosis [11]. Different kinds of DNA damage cause distinct changes in histone biotinylation: double-stranded breaks of DNA decrease histone biotinylation [12], whereas formation of thymine dimers in DNA increases biotinylation of histones [13].

\subsection{Poly(ADP-ribosylation) of histones and other DNA-binding proteins}

Double-stranded DNA breaks require repair by either nonhomologous end joining or homologous recombination in order to prevent tumor initiation. If damage is beyond repair capabilities, apoptosis is triggered to prevent propagation of abnormal cells. Covalent modifications of DNAbinding proteins play important roles in DNA repair and apoptosis. Poly(ADP-ribose) polymerase (PARP) binds to the DNA near strand breaks; binding is associated with activation of the polymerase. PARP catalyzes the covalent attachment of linear and branched chains of poly(ADPribose) residues on itself (automodification) and other acceptor proteins [14]. For example, poly(ADP-ribosylation) of histones $\mathrm{H} 2 \mathrm{~A}$ and $\mathrm{H} 2 \mathrm{~B}$ increases dramatically in response to DNA breaks [5,15]. Poly(ADP-ribose) chains may contain >200 ADP-ribose residues [14]. Poly(ADPribosylation) of proteins is a reversible process; degradation of poly(ADP-ribose) chains is mediated by poly(ADPribose) glycohydrolase [14]. The half-life of poly(ADPribose) in response to DNA damage is $<1 \min$ [16].

PARP plays a role in DNA repair, recombination, apoptosis and maintenance of genomic stability $[14,16]$. PARP interacts with proteins from the DNA excision repair machinery [16]. PARP-null mice are extremely sensitive to genotoxic stressors [16] and are at increased risk for sister chromatid exchanges.

PARP uses NAD as a substrate for generating poly(ADPribose) chains [16]. In mammals, nicotinamide adenine dinucleotide (NAD) can be synthesized from either niacin or tryptophan $[17,18]$. Consistent with a predominant role for 

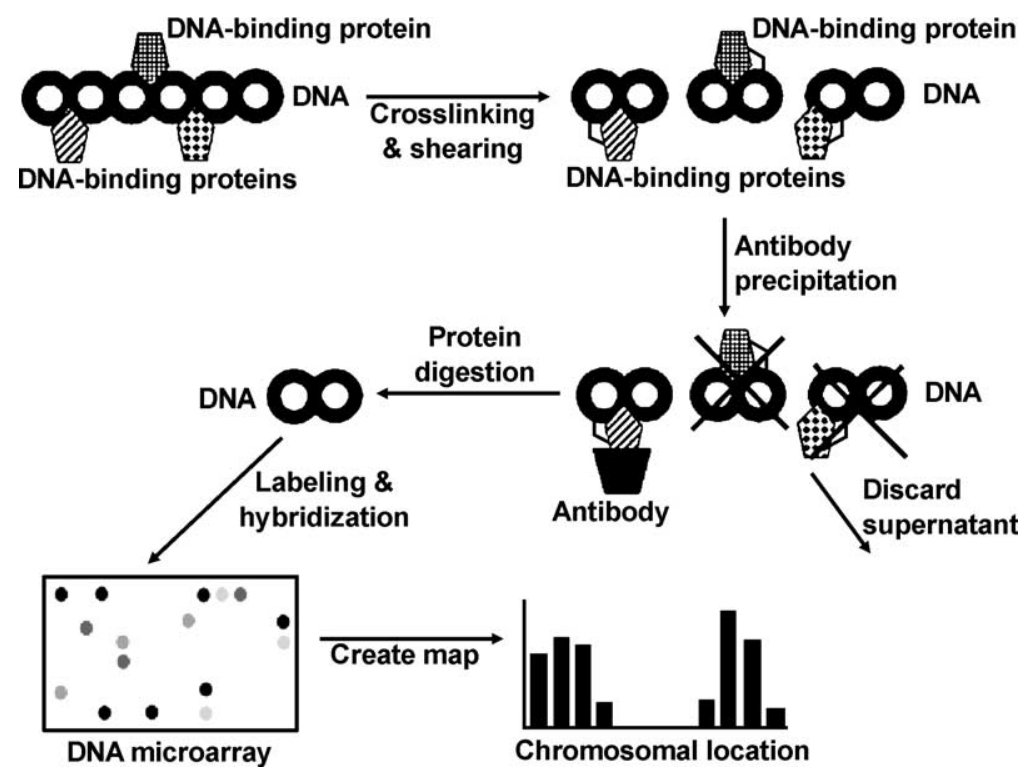

Fig. 1. Creating epigenetic road maps by using ChIP assays in combination with DNA microarrays.

niacin in NAD synthesis, poly(ADP-ribosylation) of proteins correlates with niacin supply in mammals [16]. Niacin supplementation may reduce the frequency of DNA damage in human lymphocytes [16].

\section{Characterization of epigenetic events by using ChIP assays and DNA microarrays}

Nutritional biochemists can benefit greatly from being in full command of tools to investigate epigenetic events. Ground can be lost rapidly in the genomics era by not taking advantage of cutting-edge technology. Recently, a novel analytical procedure that is likely to impact the field of epigenetics dramatically has become available: the combined use of ChIP assays and DNA microarrays [19,20]. This procedure is designed to map epigenetic marks in the entire genome of any given species. This procedure is also an excellent tool to map the enzymes that mediate modifications of DNA and DNA-binding proteins in chromatin. The combination of ChIP assays and DNA microarrays holds great promise for the identification of roles for nutrients in epigenetic events, given the extraordinary power of this new tool.

What is the working principle of ChIP assays/DNA microarrays? Briefly, this procedure uses the following analytical sequence to map epigenetic marks in chromatin (Fig. 1): (1) DNA and proteins in chromatin are cross-linked using formaldehyde, and chromatin is sheared to produce fragments of 500-1500 base pairs in size; (2) chromatin is immunoprecipitated using an antibody that binds the epigenetic mark of interest; the supernatant does not contain the mark of interest and is discarded; (3) DNA is purified from the precipitated chromatin; (4) DNA is chemically labeled (e.g., by using fluorophores) and is hybridized to DNA microarrays; and (5) the epigenetic mark of interest is mapped in the genome, based on its relative enrichment by antibody precipitation. The information obtained can be used in various ways. For example, the relative enrichment of a given epigenetic mark in a distinct region of chromatin can be correlated with the transcriptional activity of genes residing in that region.

The generation of epigenetic road maps in chromatin depends on the availability of two diagnostic tools: ChIPgrade antibodies for immunoprecipitations and DNA microarrays that contain probes for both coding and noncoding regions in the genomes to be investigated. Nowadays, a relatively large and ever-increasing selection of ChIP-grade antibodies is available from various commercial sources. Also, antibodies can be generated by individual investigators using commercial facilities at reasonable cost. Hence, lack of appropriate antibodies may not be a limiting factor for most researchers who are conducting ChIP assays. In contrast, the current lack of appropriate DNA microarrays hampers studies described above. The vast majority of DNA microarrays contains probes for coding regions in genomes but does not contain probes for noncoding regions. Note that noncoding regions contain the majority of regulatory sequences of genes and, hence, are the prime target for many epigenetic modifications. Likely, an increasing number of DNA microarrays that overcome these early limitations will become available in the near future. Currently, however, investigators will need to rely on using customized DNA microarrays, generated either "in house" or by commercial suppliers [21]. Also, some DNA microarrays that contain probes for both coding and noncoding regions in the human genome are emerging. For example, Affymetrix, Inc. ${ }^{1}$ has developed a DNA microarray that contains probes

\footnotetext{
${ }^{1}$ Mention of trade names or commercial products in this article is solely for the purpose of providing specific information and does not imply recommendation or endorsement by the US Department of Agriculture.
} 
for coding and noncoding regions from the entire human chromosomes 21 and 22 [22]. Finally, investigators may want to consider using alternative techniques such as "chromatin immunoprecipitation arbitrarily primed PCR assay," in which immunoprecipitated DNA is amplified using random GC-rich or non-GC-rich primers to allow for random analysis of the entire genome [23].

The experimental procedures outlined here are likely to generate knowledge in areas pertinent to human health. For example, cancer is a manifestation of both abnormal genetic and epigenetic events. The combined use of ChIP assays and DNA microarrays is an excellent approach to investigate anticancer roles for nutrients such as folate, biotin and niacin based on the evidence provided above. Likewise, ChIP assays and DNA microarrays are a unique tool to investigate roles for nutrients in gene silencing during embryonic development.

\section{Acknowledgment}

This work was supported by NIH grants DK 60447, DK063945 and 1 P20 RR16469 (BRIN Program of the National Center for Research Resources) and by the NSF Epscor grant EPS-0346476. This paper is a contribution of the University of Nebraska Agricultural Research Division, Lincoln, NE 68583 (Journal Series No. 14688).

\section{References}

[1] Christman JK. Diet, DNA methylation and cancer. In: Zempleni J, Daniel $\mathrm{H}$, editors. Molecular nutrition. Wallingford (UK): CAB International; 2003. p. 237-65.

[2] Wolffe A. Chromatin. San Diego (Calif): Academic Press; 1998.

[3] Fischle W, Wang Y, Allis CD. Histone and chromatin cross-talk. Curr Opin Cell Biol 2003;15:172-83.

[4] Jenuwein T, Allis CD. Translating the histone code. Science 2001;293:1074-80.

[5] Boulikas T, Bastin B, Boulikas P, Dupuis G. Increase in histone poly(ADP-ribosylation) in mitogen-activated lymphoid cells. Exp Cell Res 1990;187:77-84.

[6] Shiio Y, Eisenman RN. Histone sumoylation is associated with transcriptional repression. Proc Natl Acad Sci U S A 2003; 100:13225-30.

[7] Camporeale G, Shubert EE, Sarath G, Cerny R, Zempleni J. K8 and K12 are biotinylated in human histone H4. Eur J Biochem 2004; 271:2257-63.
[8] Sarath G, Kobza K, Rueckert B, Camporeale G, Zempleni J, Haas E. Biotinylation of human histone $\mathrm{H} 3$ and interactions with biotinidase. FASEB J 2004;18:A103.

[9] Hymes J, Fleischhauer K, Wolf B. Biotinylation of histones by human serum biotinidase: assessment of biotinyl-transferase activity in sera from normal individuals and children with biotinidase deficiency. Biochem Mol Med 1995;56:76-83.

[10] Narang MA, Dumas R, Ayer LM, Gravel RA. Reduced histone biotinylation in multiple carboxylase deficiency patients: a nuclear role for holocarboxylase synthetase. Hum Mol Genet 2004;13:15-23.

[11] Camporeale G, Kothapalli N, Sarath G, Zempleni J. Biotinylation of histones in human cells. In: Zempleni J, Dakshinamurti K Editors. Nutrients and cell signaling. New York (NY): Marcel Dekker; 2004 [in press].

[12] Kothapalli N, Zempleni J. Double strand breaks of DNA decrease biotinylation of lysine-12 in histone H4 in JAr cells. FASEB J 2004; 18:A103-4 [abstract].

[13] Peters DM, Griffin JB, Stanley JS, Beck MM, Zempleni J. Exposure to UV light causes increased biotinylation of histones in Jurkat cells. Am J Physiol Cell Physiol 2002;283:C878-84.

[14] D'Amours D, Desnoyers S, D'Silva I, Poirier GG. Poly(ADPribosyl)ation reactions in the regulation of nuclear functions. Biochem J 1999;342(Pt 2):249-68.

[15] Boulikas T. DNA strand breaks alter histone ADP-ribosylation. Proc Natl Acad Sci U S A 1989;86:3499-503.

[16] Spronck JC, Kirkland KB. Niacin status, poly(ADP-ribose) metabolism and genomic instability. In: Zempleni J, Daniel H, editors. Molecular nutrition. Wallingford (UK): CAB International; 2003. p. 277-91.

[17] Garrett RH, Grisham CM. Biochemistry. Fort Worth (Tex): Saunders College Publishing; 1995.

[18] National Research Council CM. Dietary reference intakes for thiamin, riboflavin, niacin, vitamin B6, folate, vitamin B12, pantothenic acid, biotin, and choline (Food and Nutrition Board, Institute of Medicine). Washington (DC): National Academy Press; 1998.

[19] Weinmann AS, Farnham PJ. Identification of unknown target genes of human transcription factors using chromatin immunoprecipitation. Methods 2002;26:37-47.

[20] Chua YL, Mott E, Brown AP, MacLean D, Gray JC. Microarray analysis of chromatin-immunoprecipitated DNA identifies specific regions of tobacco genes associated with acetylated histones. Plant J 2004;37:789-800.

[21] NimbleGen, Inc. Using chromatin immunoprecipitations (ChIP) to determine protein binding sites on DNA. Madison (Wis): NimbleGen Systems, Inc; 2003.

[22] Kapranov P, Cawley SE, Drenkow J, Bekiranov S, Strausberg RL, Fodor SP, et al. Large-scale transcriptional activity in chromosomes 21 and 22. Science 2002;296:916-9.

[23] Liang G, Lin JC, Wei V, Yoo C, Cheng JC, Nguyen CT, et al. Distinct localization of histone $\mathrm{H} 3$ acetylation and $\mathrm{H} 3-\mathrm{K} 4$ methylation to the transcription start sites in the human genome. Proc Natl Acad Sci U S A 2004; 101:7357-62. 